\title{
A Hybrid Web-Based and In-Person Self-Management Intervention Aimed at Preventing Acute to Chronic Pain Transition After Major Lower Extremity Trauma: Feasibility and Acceptability of iPACT-E-Trauma
}

Mélanie Bérubé ${ }^{1,2}$, MSc; Céline Gélinas ${ }^{2,3}, \mathrm{PhD}$; Nancy Feeley ${ }^{2,3}, \mathrm{PhD}$; Géraldine Martorella ${ }^{4}$, PhD; José Côté ${ }^{5,6}$, $\mathrm{PhD}$; G Yves Laflamme ${ }^{7}, \mathrm{MD}$; Dominique M Rouleau ${ }^{7}, \mathrm{MD}, \mathrm{MSc} ;$ Manon Choinière ${ }^{6,8}, \mathrm{PhD}$

${ }^{1}$ Centre intégré universitaire du Nord-de-l'Île-de-Montréal, Hôpital du Sacré-Coeur de Montréal, Trauma Program and Department of Nursing, Montreal, QC, Canada

${ }^{2}$ Ingram School of Nursing, McGill University, Montreal, QC, Canada

${ }^{3}$ Centre for Nursing Research, Jewish General Hospital, Montreal, QC, Canada

${ }^{4}$ College of Nursing, Florida State University, Tallahassee, FL, United States

${ }^{5}$ Faculté des sciences infirmières, Université de Montréal, Montreal, QC, Canada

${ }^{6}$ Centre de recherche du Centre hospitalier de l'Université de Montréal, Montreal, QC, Canada

${ }^{7}$ Centre intégré universitaire du Nord-de-l'Île-de-Montréal, Hôpital du Sacré-Coeur de Montréal, Department of Surgery, Université de Montréal, Montreal, QC, Canada

${ }^{8}$ Department of Anesthesiology, Université de Montréal, Montreal, QC, Canada

\section{Corresponding Author:}

Mélanie Bérubé, MSc

Centre intégré universitaire du Nord-de-l'Île-de-Montréal, Hôpital du Sacré-Coeur de Montréal

Trauma Program and Department of Nursing

5400 Boulevard Gouin Ouest

Montreal, QC, H4J 1C5

Canada

Phone: 15143382222 ext 2654

Fax: 15143383139

Email: melanie.berube2@mail.mcgill.ca

\begin{abstract}
Background: A transition from acute to chronic pain frequently occurs after major lower extremity trauma. While the risk factors for developing chronic pain in this population have been extensively studied, research findings on interventions aiming to prevent chronic pain in the trauma context are scarce. Therefore, we developed a hybrid, Web-based and in-person, self-management intervention to prevent acute to chronic pain transition after major lower extremity trauma (iPACT-E-Trauma).

Objective: This study aimed to assess the feasibility and acceptability of iPACT-E-Trauma.

Methods: Using a descriptive design, the intervention was initiated at a supra-regional level-1 trauma center. Twenty-eight patients $\geq 18$ years old with major lower extremity trauma, presenting with moderate to high pain intensity 24 hours post-injury were recruited. Feasibility assessment was two-fold: 1) whether the intervention components could be provided as planned to $\geq 80 \%$ of participants and 2) whether $\geq 80 \%$ of participants could complete the intervention. The rates for both these variables were calculated. The E-Health Acceptability Questionnaire and the Treatment Acceptability and Preference Questionnaire were used to assess acceptability. Mean scores were computed to determine the intervention's acceptability.

Results: More than $80 \%$ of participants received the session components relevant to their condition. However, the Web pages for session 2, on the analgesics prescribed, were accessed by $71 \%$ of participants. Most sessions were delivered according to the established timeline for $\geq 80 \%$ of participants. Session 3 and in-person coaching meetings had to be provider earlier for $\geq 35 \%$ of participants. Session duration was 30 minutes or less on average, as initially planned. More than $80 \%$ of participants attended sessions and $<20 \%$ did not apply self-management behaviors relevant to their condition, with the exception of deep breathing relaxation exercises which was not applied by $40 \%$ of them. Web and in-person sessions were assessed as very acceptable (mean scores $\geq 3$ on a 0 to 4 descriptive scale) across nearly all acceptability attributes.
\end{abstract}


Conclusions: Findings showed that the iPACT-E-Trauma intervention is feasible and was perceived as highly acceptable by participants. Further tailoring iPACT-E-Trauma to patient needs, providing more training time for relaxation techniques, and modifying the Web platform to improve its convenience could enhance the feasibility and acceptability of the intervention.

Trial Registration: International Standard Randomized Controlled Trial Number (ISRCTN): 91987302; http://www.controlled-trials.com/ISRCTN91987302 (Archived by WebCite at http://www.webcitation.org/6ynibjPHa)

(JMIR Formativ Res 2018;2(1):e10323) doi: $\underline{10.2196 / 10323}$

\section{KEYWORDS}

Acute pain; chronic pain; wound and injuries; lower extremity; self-care; health promotion; feasibility studies; patient acceptance of health care

\section{Introduction}

\section{Background}

Most trauma patients suffer from an orthopedic injury [1,2] resulting in a high prevalence of disabling chronic pain affecting up to $86 \%$ of patients from several months to years post-trauma [3-5]. Considering the negative impacts of chronic pain on the quality of life of trauma patients [3,5-8] and associated social expenditure [9-13], several studies have focused on risk factors that could trigger acute to chronic pain transition in this population [3-5]. Some risk factors have been consistently identified across studies, including moderate to high acute intensity pain, major lower extremity trauma (ET; ie, patients who usually require hospitalization for surgical and multidisciplinary team acute care management), and psychological variables (eg, anxiety, depression, pain catastrophizing, pain-related fear).

Despite a growing acknowledgment of the issues associated with chronic pain in orthopedic trauma and evidence on identified risk factors, intervention studies aiming to prevent chronic pain in this population are still scarce [14,15]. Indeed, most studies on chronic pain preventive interventions have been conducted in back pain patients [16-27] and, more recently, in the context of nontrauma related major surgery [28]. These preventive interventions were designed according to a cognitive-behavioral approach, where the objective is to promote self-management behaviors, ie, skills to control pain and its effect on physical and psychological functioning [29,30]. Preliminary findings on the efficacy of these interventions showed promising results. These included decreased pain intensity and/or disability [17,18,24-26,28], reduced opioid use [28], as well as improved psychological well-being [17,22,25] or more rapid return to work [16,19-21,27]. Hence, we developed a self-management intervention aimed at preventing acute to chronic pain transition in major lower extremity trauma (iPACT-E-Trauma) patients [31,32], a population at high-risk of developing chronic pain.

The iPACT-E-Trauma was developed according to a systematic approach, to address common factors involved in the transition from acute to chronic pain and meet the needs of patients with major lower ET [31,32]. We used empirical evidence from prior research on chronic pain preventive interventions, the biopsychosocial model of chronic pain [33], and clinical knowledge of the population to determine the main features of iPACT-E-Trauma (ie, what, who, how, where, when and how much) [34]. Then, acceptability was tested with ten clinicians (ie, nurses, orthopedic surgeons, a psychiatrist, a family physician specialized in pain management, and physiotherapists) from interdisciplinary trauma teams followed by 6 ET patients who received the intervention [32]. Both clinicians and patients found the preliminary features of iPACT-E-Trauma to be acceptable. Nonetheless, refinements were made to the intervention based on the results of an acceptability questionnaire, data gathered during a focus group with clinicians, and individual interviews with patients. Findings from the acceptability questionnaire were presented to clinicians during the focus group with them, which allowed the identification of the refinements needed. The clinicians underscored the need to improve the intervention's suitability for ET patients. To this end, the complexity of proposed activities and session duration were reduced, making the intervention more likely to be adhered to by participants. Also, clinicians proposed to develop web sessions to facilitate the delivery of the intervention by busy health care professionals during patient's hospitalization. The patients' acceptability assessment highlighted the importance of tailoring the activities and timelines according to their pain intensity, pain interference with activities, implementation of self-management behaviors, and recovery pace.

The aims of this study were the following: 1) evaluate the refined version of iPACT-E-Trauma feasibility, and 2) examine its acceptability in patients with major lower ET. Feasibility and acceptability criteria as described by Sidani and Braden [35] were used in this study. Feasibility refers to the practicality of implementing the intervention, focusing on the capability to carry out components and activities as planned and identifying issues in the implementation of the intervention. Variations in implementation can occur at different levels, either with the interventionist or with the clients receiving it and who are expected to carry out recommendations in their day-to-day life [35]. Acceptability is the perceived value or attitude toward the intervention by the client. This is operationalized in different ways. First, the extent to which the intervention is effective and appropriate in addressing the presenting problem, second, whether it is convenient and poses minimal risk, and third, whether participants are willing to adhere to the intervention [35]. 


\section{Methods}

\section{Design}

A descriptive design was used. The participants were patients who received the intervention and were randomly assigned to the experimental group of a pilot randomized clinical trial (RCT) [31].

\section{Setting}

The intervention was initiated at a 554 beds supra-regional level-1 trauma center in Montreal, Canada. This center admits, on average, 1400 trauma patients annually, 400 of who have a major ET. Patients received intervention sessions during their hospital stay, and, after hospital discharge, in a rehabilitation center, at home, or during their surgical follow-up appointment at the outpatient orthopedic clinic. Ethics approval was obtained from the Centre Intégré Universitaire de Santé et de Services Sociaux du Nord de l'île-de-Montréal, Installation Hôpital du Sacré-Coeur de Montréal (HSCM) Research Ethics Board (REB) (project identification number HSCM-2017-1333) and McGill University REB (project identification A02-M15-16B). Written consent was obtained from each participants included in the study.

\section{Sample Characteristics}

Twenty-eight patients received the iPACT-E-Trauma intervention. The inclusion criteria were the following: a) age 18 years or older, b) able to read and speak French, (c) major lower ET, and d) at risk of developing chronic pain. Acute pain intensity has consistently been reported as a risk factor for a transition from acute to chronic pain in the ET population [3-5]. The Initiative on Methods, Measurement, and Pain Assessment in Clinical Trials has recommended the inclusion of this criterion in chronic pain prevention studies [36]. Consequently, patients were enrolled if they manifested a pain intensity of $\geq 4 / 10$ upon movement 24 hours post-injury, which corresponds a moderate to severe pain intensity [37], as documented by nurses in medical charts.

The exclusion criteria were the following: a) spinal cord injury, b) amputation, c) other trauma associated with high-intensity pain ( $>2$ fractured ribs [38] or surgical abdominal trauma) or principal site of pain not being lower ET, d) cognitive impairment and language limitation (ie, dementia, moderate-severe traumatic brain injury - Glasgow coma scale score $<13 / 15$ [39], administration of sedative agents, mechanical ventilation) affecting the capacity to participate in the intervention and to complete questionnaires, and e) needing more than 7 days of hospitalization before being eligible to participate in the study. Patients with pre-injury somatic pain were not excluded unless they were taking analgesics on a daily basis, and neither were patients with pre-injury visceral pain, considering that it is possible to differentiate this type of pain from musculoskeletal pain. Moreover, although substance abuse, including pre-injury opioid use, may influence pain outcomes, we did not exclude patients with this comorbid factor considering its high incidence in the trauma population [40-43] and the potential threat to the study's external validity.

\section{Intervention}

The main features of the intervention have been previously described [31,32]. The topics of the refined version of iPACT-E-Trauma were the bio-psychosocial dimensions of pain, pharmacological (including how to reduce opioids over time) and nonpharmacological strategies for acute pain management, health-promotion strategies, and return to pre-injury activities. Various strategies commonly utilized in interventions based on a cognitive-behavioral approach [44] were used, such as psychoeducation, continued monitoring, provision of feedback, problem-solving, individualized action plan for a progressive increase in activity, and matching of self-management skills with real-life situations.

Regarding structure, the refined iPACT-E-Trauma included seven sessions (five regular and two boosters) lasting between 15 and 30 minutes, provided by a nurse with a master's degree $[31,32]$. The intervention lasted three months and was initiated within seven days post-injury to allow patients to rapidly develop self-management behaviors and optimally manage their acute pain. Sessions 1 and 2 were expected to be given in the first week post-injury, sessions 3 to 5 on a weekly basis after that, and sessions 6 and 7 at six and twelve weeks post-injury, respectively. A hybrid delivery mode was utilized combining the Web (ie, Traitement et Assistance Virtuelle Infirmière et Enseignement platform - Soulage TAVIE Post-Trauma) [45,46] (Figures 1 and 2; Multimedia Appendix 1) and in-person contact with a nurse, over the phone or face-to-face in the outpatient orthopedic clinic. The first three sessions were Web-based, followed by short in-person coaching meetings during hospitalization. Web sessions were delivered with a laptop and headphones in participant room. The last four sessions were designed to be one-on-one, either in a rehabilitation setting, an outpatient orthopedic clinic, a home, or a hospital in case of a lengthy hospital stay. A participant manual was used as a support tool during in-person sessions. Web sessions and the participant manual were designed according to recommended health literacy strategies (Multimedia Appendix 2) [47,48].

\section{Variables and Measurement Tools}

Sociodemographic and clinical data were collected after participants agreed to take part in the study. A clinical profile form was used to gather data related to injuries, treatments received, and pre-injury comorbid factors. Substance abuse was determined according to the toxicology screen as well as the health questionnaire obtained soon after the arrival to the trauma center. The feasibility and acceptability of the intervention were assessed with the following tools. 
Figure 1. Introduction page of Soulage TAVIE Post Trauma.

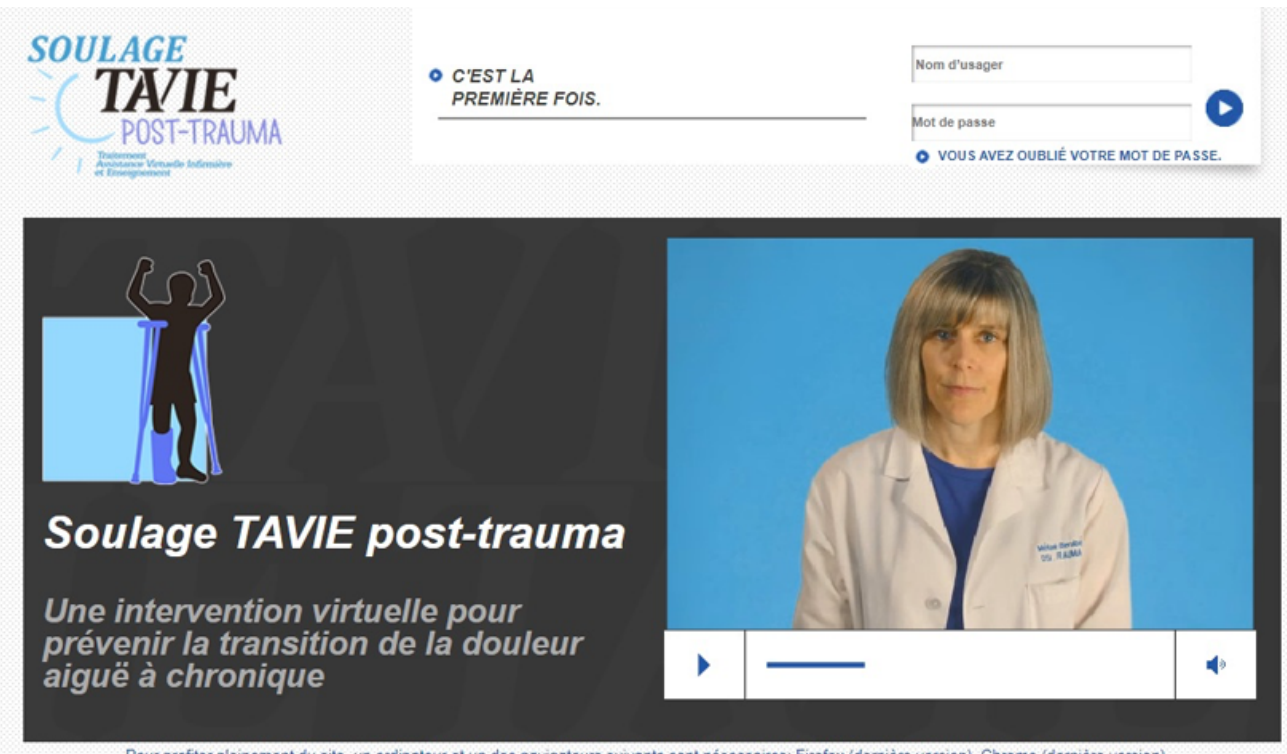

Pour profiter pleinement du site, un ordinateur et un des navigateurs suivants sont nécessaires: Firefox (demière version). Chrome (dernière version).
- CRÉDITS
- COPYRIGHT
- RÉFÉRENCES

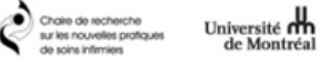
CRCHUM
Quebec 照
McGill

Figure 2. Establishing an objective for staying active after the injury.

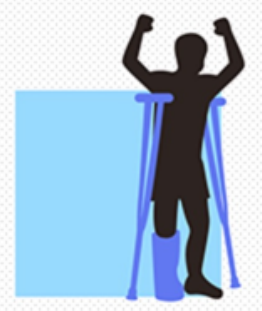

Spécifique

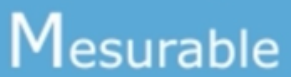

A

$\mathbf{P}$

7
De façon à vous aider à

demeurer actif, je vous invite

à vous fixer un objectif

d'activité que vous aimeriez

entreprendre d'ici la semaine prochaine. Pour ce faire, je vous encourage à utiliser la démarche SMART.

L'acronyme SMART veut dire

Spécifique, Mesurable,

Atteignable, Réalisable et

Temps précis.

Référez-vous au document " La démarche SMART " sous l'onglet " Mon coffre à outils " pour avoir accès à un exemple et vous aider à établir votre objectif d'activité à entreprendre d'ici la semaine prochaine. La réalisation de cet objectif sera révisée avec l'infirmière lors de la session 4 qui se tiendra par téléphone ou en présence de celle-ci. 


\section{Feasibility}

Intervention feasibility was assessed according to two criteria: 1) the ability to deliver the intervention as planned (ie, provision of session components to $\geq 80 \%$ of participants, length of sessions corresponded to planned duration, and the challenges faced during intervention delivery could be overcome), and 2) the capability of participants to complete the intervention (ie, attendance at sessions as well as application of self-management behaviors after sessions 1 to $6 \geq 80 \%$ of participants) [49]. We used an Intervention Feasibility Evaluation Logbook to document the delivery of session components and a Self-Management Behavior Assessment Checklist to describe participant's capability to complete the intervention.

\section{Acceptability}

Web sessions were assessed with an E-Health Acceptability Questionnaire that includes recommended features for internet-based interventions [50], and in-person sessions were assessed with an acceptability questionnaire based on the Treatment Acceptability and Preference (TAP) Questionnaire [51]. The E-Health Acceptability Questionnaire was developed to analyze the TAVIE platform content [50], and includes 21 items rated on a 5-point descriptive scale (eg, $0=$ not easy to use, 4 = very much easy to use) divided into nine subscales: ease of use, ease of understanding, credibility, tailoring, relevance, perceived applicability, visual design appreciation, dosage, motivational appeal, and overall satisfaction with the Web-based intervention. Content validation for this questionnaire was established by experts in the field of Web-based health interventions [50]. Participants completed the E-Health Acceptability Questionnaire after session 3. A high-reliability score (Cronbach alpha $=0.87$ ) was obtained for the E-Health Acceptability Questionnaire in this study.

The TAP Questionnaire is a validated and reliable tool for persons receiving self-management interventions [51], that assesses the following intervention acceptability attributes: 1) perceived effectiveness in managing the problem, 2) appropriateness, 3) suitability to individual context, and 4) convenience or willingness to apply and adhere to the intervention. Participants were instructed to rate the intervention's features based on these four attributes, using a 5-point descriptive scale (eg, $0=$ not appropriate, $4=$ very much appropriate). Open-ended questions were added at the end of each attribute section to gather input on the modifications required to improve intervention acceptability. Participants completed the TAP questionnaire after session 5 to assess the acceptability of sessions 4 and 5, and after session 7 to assess sessions 6 and 7 as well as the intervention overall. Reliability scores for acceptability questionnaires completed after sessions 5 and 7 were high when considering all four attributes (Cronbach alpha $>0.9$ ).

\section{Data Analysis}

\section{Feasibility}

To determine the ability to deliver iPACT-E-Trauma, uptake of the various components (face-to-face contacts, Web pages, and on-line documents consulted) was described. Rates of sessions delivered within the established timeline were computed. Mean scores were calculated for the time spent watching Web sessions, consulting Web pages and for the delivery of in-person sessions. Descriptive data about the challenges involved in the delivery of interventions were grouped into categories. Frequencies were calculated for each category. Rates of attendance to sessions and application of self-management behaviors were calculated regarding the capability of participants to complete the intervention.

\section{Acceptability}

Descriptive analyses of data for the acceptability questionnaires were performed. Mean scores were calculated for each acceptability attribute. The answers to the open-ended questions on the modifications required to enhance the intervention's acceptability were grouped into categories. However, less than five participants answered the open-ended questions, precluding meaningful data analysis.

Extracts from the data sets and/or analyzed and the material used during the current study are available from the corresponding author.

\section{Results}

\section{Sociodemographics}

Sociodemographic data are presented in Table 1. More than half the participants were male, and the majority were Caucasian. Mean age was 47 years, ranging from 18 to 79 years. Twenty-two out of 28 participants (78\%) had a high school to college education, and 20 participants $(72 \%)$ had an annual income $<\$ 50,000$. The most common occupation was laborer followed by work as a professional. Six participants (22\%) were retired.

\section{Clinical Data}

Data on participants' injuries and treatments are presented in Table 2. Almost half of the participants suffered an orthopedic injury secondary to a fall. The most frequent fractures were to the pelvis, the acetabulum, the femur and the tibia. Joint dislocation occurred in 13 out of 22 participants (46\%) and soft tissue injury (eg, tissue swelling delaying surgery, deep laceration, crush injury) in more than half of the participants. Almost two-thirds of the participants had at least two fractures, while half had a concomitant injury. The most frequent being a fracture to the upper extremities, followed by a fracture to the spine, and mild TBI. According to the mean Injury Severity Score (ISS) and the Abbreviated Injury Scale (AIS) - Extremity score [52] most participants suffered moderate to serious injury. The dominant comorbidities were substance abuse and mental health issues (eg, history of anxiety or depression) but were present in less than a quarter of participants. Twenty-six participants $(93 \%)$ had an open reduction and internal fixation surgery for their lower ET and, among these, 11 participants (39\%) had a lower limb immobilized by a cast or an orthosis for several weeks after the injury. Weight-bearing limitation on the injured limb was prescribed for 3 to 6 months in almost half the participants. 
Table 1. Sociodemographic data for total participants $(n=28)$.

\begin{tabular}{|c|c|}
\hline Characteristics & iPACT-E-Trauma group, n (\% ) \\
\hline \multicolumn{2}{|l|}{ Gender } \\
\hline Male & $15(54)^{\mathrm{a}}$ \\
\hline \multicolumn{2}{|l|}{ Ethnical group } \\
\hline Caucasian & $23(82)$ \\
\hline Haitian & $3(11)$ \\
\hline Arabic & $2(7)$ \\
\hline \multicolumn{2}{|l|}{ Level of education } \\
\hline$<$ High school diploma & $2(7)$ \\
\hline High school diploma & $11(39)$ \\
\hline Collegial diploma & $11(39)$ \\
\hline Undergraduate studies diploma & $3(11)$ \\
\hline Graduate studies diploma & $1(4)$ \\
\hline \multicolumn{2}{|l|}{ Occupation } \\
\hline Laborer & $6(22)$ \\
\hline Clerical work & $2(7)$ \\
\hline Administration & $4(14)$ \\
\hline Professional & $4(14)$ \\
\hline Student & $2(7)$ \\
\hline None & $4(14)$ \\
\hline Retired & $6(22)$ \\
\hline \multicolumn{2}{|l|}{ Annual income } \\
\hline$<\$ 20,000 /$ year & $6(22)$ \\
\hline$\$ 20,000$ to $\$ 49,000$ & $14(50)$ \\
\hline$\$ 50,000$ to $\$ 69,000$ & $2(7)$ \\
\hline$\$ 70,000$ to $\$ 99,000$ & $4(14)$ \\
\hline$\geq \$ 100,000$ & $2(7)$ \\
\hline
\end{tabular}

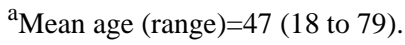

\section{Feasibility}

\section{The Ability to Deliver the Intervention as Planned}

Twenty to 28 out of 28 participants (71\% to $100 \%$ ) accessed all Web pages of sessions 1 to 3 (Table 3). During session 2, six participants $(21 \%)$ did not access Web pages about the mechanisms of action of opioids and acetaminophen, and 19 participants $(67 \%)$ did not access Web pages related to pregabalin. Most participants consulted self-management recommendation summaries in the participant's manual, while a few consulted them in the Web platform throughout Web sessions.

Components of the in-person coaching meetings relevant to all participants were provided as planned to most during the first and the second meetings, and to fewer participants during the third meeting (Table 3). Those that required individualized tailoring were also less frequently delivered. Web sessions were primarily delivered according to the established timeline, except for session 3. The timeline was less frequently followed for the in-person meetings compared to Web sessions. Mean duration for Web sessions combined with in-person coaching meetings were $\leq 30$ minutes. The challenges experienced during Web sessions were from various types, but they all occur in seven or less $(\leq 26 \%)$ of participants: 1$)$ environmental (ie, noise or limited space in participant's room), 2) technical (ie, slow internet connection, difficulty creating password), 3) participant-related (ie, drowsiness, nausea, no glasses), and 4) care-related (ie, interruptions for nursing evaluation and intervention or diagnostic tests). 
Table 2. Participants' injuries and treatments received $(n=28)$.

\begin{tabular}{lc}
\hline Characteristics & Results, \\
\hline Trauma mechanism & $8(28)$ \\
Motor vehicle crash & $3(11)$ \\
Pedestrian collision & $13(46)$ \\
Fall & $3(11)$ \\
Sport & $1(4)$ \\
Work & $1(4)$
\end{tabular}

Types of orthopedic injuries ${ }^{\mathrm{a}}$

Pelvic fracture

Acetabulum fracture

Femur fracture

Knee joint ligaments sprain

Tibia fracture

Fibula fracture

Ankle fracture

Foot fracture

Open fracture

Joint dislocation

Soft tissue

Number of fractures

One

Two

$\geq 3$

Other injuries

Participants with at least one concomitant injury

Mild traumatic brain injury

Upper extremities

Thorax

Abdomen

Spine

Injury Severity Score

Abbreviated Injury Scale (AIS) - Orthopedic score

AIS 1 (minor extremity injury)

AIS 2 (moderate extremity injury)

AIS 3 (serious extremity injury)

AIS 4 (severe extremity injury, life-threatening)

\section{Comorbidities}

Substance abuse

Somatic or visceral pain before the injury

Mobility issue requiring technical aid

Neurological (eg, epilepsy, previous stroke)

Cardiovascular (eg, previous myocardial infarction, hypertension) 


\begin{tabular}{ll}
\hline Characteristics & Results, $\mathrm{n}(\%)$ \\
\hline Psychological (eg, anxiety, depression) & $6(22)$ \\
Treatments & \\
Open reduction and internal fixation surgery & $26(93)$ \\
Closed reduction and external fixation surgery & $8(28)$ \\
Conservative treatment (no surgery) & $2(7)$ \\
Immobilization with a cast or an orthosis & $11(39)$ \\
Weight bearing limitation postinjury & $1(4)$ \\
No limitation & $14(50)$ \\
6 weeks postinjury & $10(36)$ \\
3 months postinjury & $3(11)$ \\
6 months postinjury & \\
\hline
\end{tabular}

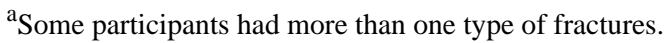

${ }^{\mathrm{b}}$ Some participants received more than one treatment.

The components of in-person sessions relevant to all participants were provided to a large proportion of participants during sessions 5 to 7 (Table 4), while those requiring individualized tailoring were delivered to fewer participants. In-person sessions were offered according to the established timeline to most of the participants. Their mean duration was also $\leq 30$ minutes. Challenges experienced during sessions 4 to 7 were related to participants (ie, lack of motivation, emphasizing other problems than pain), to care (ie, difficulty coordinating sessions with other interventions occurring at the outpatient orthopedic clinic), and to the environment (ie, noise in participant's room). These were present for less than three participants $(<10 \%)$.

\section{The Capability of Participants to Complete the Intervention}

\section{Attendance at the Intervention Sessions}

The Web sessions and in-person coaching meetings were attended by all participants for the first two sessions and by 26 out of 28 participants (93\%) for the third session (Table 5). The in-person sessions were attended by all participants for session 4, by $26(93 \%)$ for sessions 5 and 6, and by 25 (89\%) for session 7 (Table 5).

\section{Application of Self-Management Behaviors}

Overall, less than six over 28 participants $(<20 \%)$ did not apply self-management behaviors relevant to their condition (Table 5). Cryotherapy was applied by two-thirds of participants after session 1 and by more than half after session 3 and diminished as the intervention progressed. Cryotherapy was not indicated in several participants after sessions 1 to 4 given they had limb immobilization with a thick elastic bandage, splint cast with an elastic bandage or skin vascularization issues. Following sessions 5 and 6, cryotherapy was not indicated in 18 participants $(70 \%)$ because pain intensity did not interfere with activities, there was no significant limb swelling, or a splint covered by a thick elastic bandage immobilized the limb. Leg

elevation, a self-management behavior suggested in the first session, was strongly followed from sessions 1 to 3 , and as was the case with cryotherapy, its use gradually declined afterward. Leg elevation was not needed in some participants after sessions 1 and 2, considering localized pelvic fractures without associated swelling, and even more after sessions 3 to 7 (reaching up to 20 participants or more than $75 \%$ of them) as the gradual decrease in swelling and pain intensity helped participants resume activities.

Appropriate use of co-analgesia was implemented by all but one participant after session 1 and in about two thirds after session 4, after which co-analgesia was not needed in up to $44 \%$ of participants, as they were either only taking acetaminophen or no analgesic. Almost half the participants did not use the deep breathing relaxation exercises they were taught in session 2. Relaxation exercises were not indicated anymore for many participants after sessions 4 to 7 because there was no marked pain interference with activities (score<4/10) [37]. Problem-solving, when facing a difficult pain experience, was used by 10 participants (36\%) after session 3 and three participants (10\%) after session 6. However, this self-management behavior did not apply to many participants and was found irrelevant. Moreover, few participants needed to establish sleep hygiene objectives and apply strategies to facilitate sleep over the course of the intervention sessions.

The objective of remaining active without increasing pain intensity and the individualized plans for returning to previous activities were highly achieved by participants. Mobility restrictions prevented some participants from reaching their objectives for staying active. Regarding strategies, several participants used the gradual return to activities, while fewer participants used activity pacing or changing the activity schedule in light of pain intensity variations throughout the day. These two latter strategies were not indicated for several participants since they were not yet active enough. 
Table 3. Delivery of web sessions (1 to 3 ) and related in-person coaching meetings.

\begin{tabular}{|c|c|}
\hline Variables & Results \\
\hline \multicolumn{2}{|l|}{ Session 1} \\
\hline \multicolumn{2}{|l|}{ Web $(n=28), n(\%)$} \\
\hline Participants who accessed all web pages & $28(100)$ \\
\hline Summaries accessed in the web platform & $4(14)$ \\
\hline Summaries consulted in the participant manual & $24(85)$ \\
\hline Session delivered according to the established timeline & $28(100)$ \\
\hline Session duration, mean (SD; range) & $18 \min (6 ; 13-34)$ \\
\hline \multicolumn{2}{|l|}{ In-person coaching $(n=28)$} \\
\hline \multicolumn{2}{|l|}{ Components provided to participants, $\mathrm{n}(\%)$} \\
\hline Answer questions related to the on-line content & $27(96)$ \\
\hline Ask participants to report their pain intensity & $28(100)$ \\
\hline Ask participants to report their ice and legs elevation utilization & $28(100)$ \\
\hline Review how to use ice and legs elevation if needed & $12(46)$ \\
\hline Tailor the recommendations on cryotherapy and legs elevation if needed & $17(61)$ \\
\hline Meeting delivered according to the established timeline, $\mathrm{n}(\%)$ & $12(43)$ \\
\hline Meeting duration, mean (SD; range) & $4 \min (2 ; 2-10)$ \\
\hline \multicolumn{2}{|l|}{ Session 2} \\
\hline \multicolumn{2}{|l|}{ Web $(n=28), n(\%)$} \\
\hline Participants who accessed all web pages & $20(71)$ \\
\hline Summaries accessed in the web platform & $4(14)$ \\
\hline Summaries consulted in the participant manual & $24(86)$ \\
\hline Session delivered according to the established timeline & $27(96)$ \\
\hline Session duration, mean (SD; range) & $20 \min (7.4 ; 11-47)$ \\
\hline \multicolumn{2}{|l|}{ In-person coaching $(n=28)$} \\
\hline \multicolumn{2}{|l|}{ Components provided to participants, $\mathrm{n}(\%)$} \\
\hline Answer questions related to the on-line content & $27(96)$ \\
\hline Ask participants to report their pain intensity & $27(96)$ \\
\hline Ask participant to report their co-analgesia, ice and legs elevation utilization & $28(100)$ \\
\hline Review how to use co-analgesia, relaxation exercises ice and legs elevation & $16(57)$ \\
\hline Tailor the recommendations on co-analgesia if needed & $4(14)$ \\
\hline Tailor the recommendations on cryotherapy and legs elevation if needed & $8(29)$ \\
\hline Meeting delivered according to the established timeline, $\mathrm{n}(\%)$ & $16(57)$ \\
\hline Meeting duration, mean (SD; range) & $6 \min (3 ; 2-15)$ \\
\hline \multicolumn{2}{|l|}{ Session 3} \\
\hline \multicolumn{2}{|l|}{ Web $(n=26), n(\%)$} \\
\hline Participants who accessed all web pages & $25(96)$ \\
\hline Summaries accessed in the web platform & $2(8)$ \\
\hline Summaries consulted in the participant manual & $24(92)$ \\
\hline Session delivered according to the established timeline & $17(65)$ \\
\hline Session duration, mean (SD; range) & $16 \min (4 ; 8-33)$ \\
\hline \multicolumn{2}{|l|}{ In-person coaching (n=26) } \\
\hline Components provided to participants, $\mathbf{n}(\%)$ & \\
\hline
\end{tabular}




\begin{tabular}{lll}
\hline Variables & & Results \\
\hline Answer questions related to the on-line content & $16(62)$ \\
Ask participants to report their pain intensity & $13(50)$ \\
Ask participants to report their co-analgesia and relaxation exercises utilization & $14(54)$ \\
Review how to use co-analgesia and relaxation exercises if needed & $10(39)$ \\
$\quad$ Tailor the recommendations on co-analgesia if needed & $5(19)$ \\
$\quad$ Invite participants to discuss the use of problem solving if indicated & $9(35)$ \\
$\quad$ Assist participants in the establishment of an activity objective & $26(100)$ \\
Meeting delivered according to the established timeline, $\mathrm{n}(\%)$ & $4(15)$ \\
Meeting duration, mean (SD; range) & 8 min (6; 2-23)
\end{tabular}

\section{Acceptability}

Web sessions were assessed as very acceptable nearly across all acceptability attributes (Table 6). Visual appeal (ie, colors, pictures, and pages outlook) and applicability (ie, perceived capacity to apply strategies recommended in Web sessions) were rated as acceptable, on average. In-person weekly sessions 4 and 5 were also assessed by participants as very acceptable for almost every attribute (Table 7). Items that were evaluated as acceptable included the perceived effectiveness of establishing an individualized action plan for returning to pre-injury activities, defining objectives to achieve adequate sleep hygiene, and reviewing previously learned self-management strategies at the beginning of each session. In-person sessions 6 and 7 (ie, booster sessions) were assessed as acceptable to very acceptable (Table 7). Items with the lowest mean scores across acceptability attributes were the following: reviewing the individualized action plan to return to pre-injury activity and establishing a new action plan, as well as the convenience of phone sessions. 
Table 4. Delivery of in-person sessions (4 to 7).

\begin{tabular}{ll}
\hline Variables & Results \\
\hline Session 4: in-person (n=28) & $27(96)$ \\
Components provided to participants, $\mathbf{n}(\boldsymbol{\%})$ & $28(100)$ \\
Ask participants to report their pain intensity & $20(71)$ \\
Ask participants to report their analgesics utilization & $10(36)$ \\
Encourage the application of learned self-management behaviors if needed & $11(39)$ \\
Provide information on gradual reduction of analgesics if needed & $26(93)$ \\
Discuss the use of problem solving if indicated & $24(86)$ \\
Provide feedback on the achievement of activity objective & $28(100)$ \\
Offer assistance in the establishment of another activity objective & $9(32)$ \\
Provide information on sleep hygiene & $14(50)$ \\
Provide assistance in the establishment of a sleep hygiene objective if needed & $26(93)$ \\
$\quad$ Encourage the use of strategies to optimize sleep if needed & 19 min (7; 8-38)
\end{tabular}

\section{Session 5: in-person $(n=26)$}

\section{Components provided to participants, $\mathbf{n}(\%)$}

Ask participants to report their pain intensity

Ask participants to report their analgesics utilization

Encourage the application of learned self-management behaviors if needed

Provide information on gradual reduction of analgesics utilization if needed

Provide feedback on the achievement of sleep hygiene objective

Encourage the continuous use of strategies to optimize sleep if needed

Providing feedback on the achievement of activity objective

Give information on how to return to pre-injury activities if needed

Provide assistance for establishing a plan for returning to pre-injury activities

Session delivered according to the established timeline, $\mathrm{n}(\%)$

Session duration, mean (SD; range)

$20 \min (6 ; 12-31)$

\section{Session 6 (Booster 1): in-person $(n=26)$}

\section{Components provided to participants, $\mathbf{n}(\%)$}

Answer questions related to pain management strategies

Ask participants to report their analgesics utilization

$26(100)$

Give information on gradual reduction of analgesics if needed

Provide feedback on action plan achievement

Provide assistance for reviewing the plan for returning to pre-injury activities

Reinforce the importance of using learned self-management behaviors to facilitate the return to preinjury activities if needed

Session delivered according to the established timeline, $\mathrm{n}(\%)$

Session duration, mean (SD; range)

$18 \min (8 ; 7-50)$

\section{Session 7 (Booster \#2): in-person $(n=25)$}

\section{Components provided to participants, $n(\%)$}




\begin{tabular}{ll}
\hline Variables & Results \\
\hline Give information on gradual reduction of analgesics utilization if indicated & $6(24)$ \\
Providing feedback on action plan achievement & $25(100)$ \\
Provide assistance for reviewing the plan for returning to activities & $24(96)$ \\
$\quad \begin{array}{l}\text { Reinforce the importance of using learned self-management behaviors to facilitate the return to pre- } \\
\text { injury activities if required }\end{array}$ & $19(76)$ \\
Session delivered according to the established timeline, $\mathrm{n}(\%)$ & $24(96)$ \\
Session duration, mean (SD; range) & 15 min (5; 10-30)
\end{tabular}


Table 5. Intervention completion by participants $(\mathrm{N}=28)$.

\begin{tabular}{|c|c|c|c|}
\hline Variables & Applied, n (\%) & $\begin{array}{l}\text { Not applied as recommended } \\
\text { or not applied, } \mathrm{n}(\%)\end{array}$ & Not indicated, n (\%) \\
\hline
\end{tabular}

Session $1(n=28)$

Behaviors applied between session 1 and 2

Cryotherapy (every $2 \mathrm{~h}$ for $20 \mathrm{~min}$ )

Legs elevation in straight position while in bed

Session $2(n=28)$

Behaviors applied between session 2 and 3

Cryotherapy

Legs elevation in straight position

Co-analgesia

Breathing relaxation exercises when experiencing pain interference with activities

\section{Session $3(n=26)$}

Behavior applied between session 3 and $4^{\text {b }}$

Cryotherapy

Legs elevation in straight position

Co-analgesia

Breathing relaxation exercises

Problem solving

Implementation of the activity objective

Gradual return to activities

Changing schedule of activities in light of pain

Activity pacing

Session $4(n=28)$

Behavior applied between session 4 and $5^{c}$

Co-analgesia (with reduction of opioids)

Problem solving

Implementation of the activity objective

Gradual return to activities

Changing schedule of activities in light of pain

Activity pacing

Implementation of sleep hygiene objective

Strategies to facilitate sleep

Other pain management strategies

Breathing relaxation exercises

Cryotherapy

Legs elevation

Session $5(n=26)$

Behaviors applied between session 5 and 6

Co-analgesia (with reduction of opioids)

Implementation of the action plan

Gradual return to activities
24 (86)

17 (61)

4 (14)

1 (3)

3 (11)

11 (39)

3 (11)

2 (7)

1 (4)

11 (39)

6 (21)

16 (57)

5 (18)

7 (25)

18 (64)

3 (11)

7 (25)

22 (79)

8 (29)

2 (7)

4 (14)

8 (29)

10 (36)

24 (86)

$2(43)$

13 (46)

25 (89)

5 (18)

5 (18)

3 (11)

3 (11)

19 (68)

15 (57)

4 (14)

11 (39)

1 (3)

8 (31)

10 (39)

$1(4)$

15 (58)

20 (77)

5 (19)

1 (4)

21 (81)

1 (4)

4 (15)

3 (12)

1 (4)

22 (85)

18 (69)

8 (31)

2 (8)

8 (31)

16 (62)

10 (39)

16 (62)

4 (15)

6 (23)

16 (62)

12 (46)

1 (4)

13 (50)

13 (50)

$13(50)$
$17(65)$

$24(92)$

18 (69)
$1(4)$

$8(31)$

$2(8)$

3 (12)
-

5 (19) 


\begin{tabular}{|c|c|c|c|}
\hline Variables & Applied, n (\%) & $\begin{array}{l}\text { Not applied as recommended } \\
\text { or not applied, } \mathrm{n}(\%)\end{array}$ & Not indicated, $\mathrm{n}(\%)$ \\
\hline Changing schedule of activities in light of pain & $3(12)$ & $21(81)$ & $2(8)$ \\
\hline Activity pacing & $17(65)$ & $1(4)$ & $8(31)$ \\
\hline \multicolumn{4}{|l|}{ Other pain management strategies } \\
\hline Breathing exercises & $1(4)$ & $5(19)$ & $20(77)$ \\
\hline Cryotherapy & $8(31)$ & - & $18(69)$ \\
\hline Legs elevation & $5(19)$ & $1(4)$ & $20(77)$ \\
\hline Strategies to facilitate sleep & $3(12)$ & - & $23(89)$ \\
\hline Problem solving & $7(27)$ & $2(8)$ & $17(65)$ \\
\hline \multicolumn{4}{|l|}{ Session $6(n=26)$} \\
\hline \multicolumn{4}{|l|}{ Behavior applied between session 6 and $7^{d}$} \\
\hline Adequate use of analgesics (with no or minimal use of opioids) & $14(56)$ & - & $11(44)$ \\
\hline Implementation of the action plan & $25(96)$ & $1(4)$ & - \\
\hline Gradual return to activities & $21(84)$ & $1(4)$ & $3(12)$ \\
\hline Changing schedule of activity in light of pain & $3(12)$ & $2(8)$ & $20(80)$ \\
\hline Activity pacing & $18(72)$ & $6(24)$ & $1(4)$ \\
\hline \multicolumn{4}{|l|}{ Other pain management strategies } \\
\hline Breathing relaxation exercises & $1(4)$ & $4(17)$ & $19(79)$ \\
\hline Cryotherapy & $4(16)$ & $3(12)$ & $18(72)$ \\
\hline Legs elevation & $5(20)$ & $3(12)$ & $17(68)$ \\
\hline Strategies to facilitate sleep & $3(12)$ & - & $22(88)$ \\
\hline Problem solving & $3(12)$ & $1(4)$ & $21(84)$ \\
\hline
\end{tabular}

${ }^{\text {a }}$ The category does not apply to any participant.

${ }^{\mathrm{b}}$ Percentage was calculated from 28 participants since the application of self-management behaviors was verified at the beginning of session 4 . ${ }^{\mathrm{c}}$ Percentage was calculated from 26 participants since the application of self-management behaviors was verified at the beginning of session 5 .

${ }^{\mathrm{d}}$ Percentage was calculated from 25 participants since the application of self-management behaviors was verified at the beginning of session 7 . 
Table 6. Web-based sessions (1 to 3) acceptability.

\begin{tabular}{|c|c|}
\hline Web session components & Results, mean ${ }^{\mathrm{a}}(\mathrm{SD}),(\mathrm{n}=28)$ \\
\hline \multicolumn{2}{|l|}{ Navigation } \\
\hline Directives and instructions & $3.4(1.0)$ \\
\hline Web pages navigation & $3.5(1.0)$ \\
\hline \multicolumn{2}{|l|}{ Understanding } \\
\hline Language and vocabulary used by the nurse & $3.8(0.5)$ \\
\hline Content & $3.7(0.7)$ \\
\hline \multicolumn{2}{|l|}{ Credibility } \\
\hline Content and documents & $3.4(0.8)$ \\
\hline \multicolumn{2}{|l|}{ Virtual nurse and information tailoring } \\
\hline Interactions with the virtual nurse & $3.8(0.4)$ \\
\hline Perception to have received a tailored consultation & $3.4(1.0)$ \\
\hline Personalization of messages & $3.1(1.1)$ \\
\hline \multicolumn{2}{|l|}{ Individual relevance } \\
\hline Content and documents & $3.4(0.6)$ \\
\hline Appropriateness for the management of pain and for returning to activities & $3.4(0.7)$ \\
\hline Recommendations corresponding to participant's needs & $3.6(0.6)$ \\
\hline Usefulness & $3.3(0.6)$ \\
\hline \multicolumn{2}{|l|}{ Applicability } \\
\hline Videos & $3.3(0.7)$ \\
\hline Colors, pictures and pages outlook & $2.8(1.0)$ \\
\hline \multicolumn{2}{|l|}{ Dosage } \\
\hline Sessions duration & $3.1(1.1)$ \\
\hline Interval of time between each session & $3.1(1.1)$ \\
\hline Number of sessions & $3.3(0.8)$ \\
\hline \multicolumn{2}{|l|}{ Motivational appealing } \\
\hline The participant would recommend web sessions to patients with ET & $3.7(0.6)$ \\
\hline \multicolumn{2}{|l|}{ In-person coaching session } \\
\hline Relevance of follow-up made by the nurse between sessions & $3.6(0.6)$ \\
\hline Usefulness of follow-up made by the nurse between sessions & $3.5(0.7)$ \\
\hline \multicolumn{2}{|l|}{ General } \\
\hline Global satisfaction & $3.4(0.9)$ \\
\hline
\end{tabular}

${ }^{\mathrm{a}}$ Range (0-4) 
Table 7. In-person sessions (4 to 7) acceptability.

\begin{tabular}{|c|c|c|c|c|}
\hline Intervention Components and Features & $\begin{array}{l}\text { Effectiveness, } \\
\text { mean }^{\mathrm{a}}(\mathrm{SD})\end{array}$ & $\begin{array}{l}\text { Appropriateness, } \\
\text { mean }(\mathrm{SD})\end{array}$ & $\begin{array}{l}\text { Suitability, } \\
\text { mean (SD) }\end{array}$ & $\begin{array}{l}\text { Convenience, } \\
\text { mean (SD) }\end{array}$ \\
\hline \multicolumn{5}{|l|}{ Sessions 4 and $5(n=25)^{b}$} \\
\hline $\begin{array}{l}\text { Feedback and encouragements on the utilization of recommended } \\
\text { pain management strategies at the beginning of each session }\end{array}$ & $3.1(0.8)$ & $3.2(0.8)$ & $3.2(0.7)$ & $3.2(0.8)$ \\
\hline $\begin{array}{l}\text { Review of previously learned self-management strategies at the } \\
\text { beginning of each session according to participant's needs }{ }^{c}\end{array}$ & $2.9(0.8)$ & $3.0(0.8)$ & $3.2(0.8)$ & - \\
\hline Education on sleep hygiene strategies & $3.0(1.0)$ & $3.2(0.9)$ & $3.1(1.0)$ & $3.5(0.8)$ \\
\hline Establishment of an objective to attain adequate sleep hygiene & $2.7(0.9)$ & $3.0(0.9)$ & $3.0(0.9)$ & $3.2(0.7)$ \\
\hline Guidance on the gradual reduction of analgesics utilization & $3.1(0.9)$ & $3.1(0.9)$ & $3.2(1.0)$ & $3.2(1.2)$ \\
\hline Establishment of objectives to stay active & $3.0(0.8)$ & $3.2(0.8)$ & $3.1(0.8)$ & $3.0(1.0)$ \\
\hline Discussion on problem-solving utilization & $3.2(0.9)$ & $3.2(0.8)$ & $3.2(0.8)$ & $3.0(0.8)$ \\
\hline Establishment of an action plan for returning to pre-injury activities & $2.5(1.2)$ & $3.1(1.0)$ & $3.0(1.0)$ & $3.4(0.7)$ \\
\hline The number of weeks between each session (one week) ${ }^{c}$ & - & - & $3.2(0.8)$ & - \\
\hline Sessions duration ${ }^{\mathrm{c}}$ & - & - & $3.4(0.7)$ & - \\
\hline \multicolumn{5}{|l|}{ Sessions 6 and 7 (boosters; $n=23)^{b}$} \\
\hline $\begin{array}{l}\text { Review of previously learned self-management strategies at the } \\
\text { beginning of each session according to participant's needs }{ }^{c}\end{array}$ & $3.0(0.8)$ & $3.1(0.8)$ & $2.9(0.9)$ & - \\
\hline Guidance on gradual reduction of analgesics utilization & $3.0(0.8)$ & $3.5(0.6)$ & $3.2(0.7)$ & $3.1(0.8)$ \\
\hline Review of the action plan for returning to pre-injury activities & $2.7(0.9)$ & $2.9(0.9)$ & $2.9(1.0)$ & $3.0(1.0)$ \\
\hline $\begin{array}{l}\text { Establishment of a new action plan for returning to pre-injury ac- } \\
\text { tivities }\end{array}$ & $2.7(1.0)$ & $2.9(0.9)$ & $3.0(1.0)$ & $3.0(0.9)$ \\
\hline Having received sessions over the phone ${ }^{c}$ & - & - & $3.0(0.9)$ & $2.8(1.1)$ \\
\hline Having received sessions in-person ${ }^{c}$ & - & - & $3.5(0.6)$ & $3.1(0.9)$ \\
\hline The number of week between each session ${ }^{\mathrm{c}}$ & - & - & $3.1(0.9)$ & - \\
\hline Sessions duration ${ }^{\mathrm{c}}$ & - & - & $3.1(0.8)$ & - \\
\hline The sequence of the topics covered during the intervention & - & - & $3.3(0.6)$ & - \\
\hline Intervention duration (3 months) ${ }^{\mathrm{c}}$ & - & - & $3.1(0.8)$ & $3.1(1.0)$ \\
\hline $\begin{array}{l}\text { The total number of sessions included in the intervention ( } 7 \text { ses- } \\
\text { sions) }\end{array}$ & - & - & $3.0(0.7)$ & $3.0(1.0)$ \\
\hline
\end{tabular}

${ }^{\mathrm{a}}$ Range (0-4).

${ }^{\mathrm{b}} \mathrm{A}$ total of 25 participants completed the acceptability questionnaire related to sessions 4 and 5 . A total of 23 participants completed the acceptability questionnaire related to sessions 6 and 7

${ }^{\mathrm{c} O n l y}$ relevant acceptability items were assessed

\section{Discussion}

\section{Principal Findings}

This study aimed to determine the feasibility and acceptability of iPACT-E-Trauma. Findings were positive for feasibility criteria, with components for Web sessions and in-person sessions provided to $\geq 80 \%$ of participants, except components covered in Web session 2, in-person coaching meeting 3, and those that required individualized tailoring. Sessions were delivered according to the established timeline for $\geq 80 \%$ of participants, excluding session 3 and in-person coaching meetings for sessions 1 to 3 . Average session duration was $\leq 30$ minutes, as expected. Moreover, except for one participant, all the challenges faced during intervention delivery were overcome, either by assisting participants with internet use or rescheduling sessions. Regarding participants' adherence to the intervention, $\geq 80 \%$ were able to attend planned sessions. Likewise, most participants applied self-management behaviors relevant to their condition, except deep breathing relaxation exercises. Overall, session features were evaluated as very acceptable and no feature was considered as not acceptable.

Findings from this study highlighted ways to improve the feasibility and acceptability of iPACT-E-Trauma in preparation for a larger scale study. Additional tailoring of iPACT-E-Trauma 
by adjusting its content, dosage, and timing of session delivery is required to improve the ability to deliver the intervention and the capability of patients to apply self-management behaviors (ie, feasibility). Another change would be to enhance the perceived applicability of some recommended pain management strategies (ie, acceptability). Tailored interventions are based on characteristics that are unique to the person receiving it, using a combination of information or changing strategies to achieve the outcomes of interest $[53,54]$. The procedures to tailor self-management interventions involve increasing relevance or meaning of the content by including personally identifiable information and explaining how information is relevant to a person's condition (ie, personalization). This also includes making recommendations related to the targeted behaviors (ie, feedback), and adapting the intervention (ie, content, dose, delivery timing) according to individual data such as determinants of the targeted behaviors [53-55]. In this study, iPACT-E-Trauma was personalized by suggesting pain management strategies relevant for patients with lower ET and by specifying in which context such strategies were applicable. Questioning patients on pain intensity, pain interference with activities, and application of self-management behaviors at each intervention session also promoted individualized feedback and content matching, according to participants' needs.

Recent research showed that tailored Web-based and non Web-based health interventions are slightly more effective than nontailored interventions [56-59]. One of the main causes of this result is that features of tested interventions were not enough matched to the participants' profile [55-59]. Thus, in iPACT-E-Trauma, self-management recommendations to participants should be based on behaviors they can implement considering their condition, personal attributes, and recovery pace. For example, information on how to take pregabalin should only be provided to those that use this analgesic. Problem-solving in the presence of a difficult pain experience should be exclusively reinforced in participants who experience problems regulating their negative thoughts and emotions in the presence of pain. Moreover, promoting strategies for staying active and returning to previous activities should consider the participant's capacity to ambulate.

Concerning the dosage of iPACT-E-Trauma, the number of sessions (ie, less or more than 7 sessions) offered to participants should be tailored according to pain intensity, pain interference with activities, and abilities in pain self-management. For example, a greater number of sessions should be provided to participants who still experience significant pain interference with activities (ie, score $\geq 4 / 10$ ) 3 months after their injury and who still need support from a health care professional for the implementation of self-management behaviors. Fewer than 7 sessions could also be offered to participants with pain intensity $<4 / 10$ and who have restarted to ambulate on their injured $\operatorname{limb}(\mathrm{s})$.

Furthermore, the timing of in-person coaching meetings, Web session 3 and booster sessions should be revised. In-person coaching meetings were integrated between each Web-based session, since clinicians and patients emphasized the importance of keeping in direct contact with health care professionals providing the intervention during the development phase of
iPACT-E-Trauma. More frequent interactions with health care professionals have also been identified as an important strategy to increase adherence to Web-based health interventions [60,61]. In-person coaching was planned 24 hours after each Web session, to give participants enough time to implement self-management behaviors. However, this study found that in-person coaching should be offered right after Web sessions to answer questions on the content covered and tailor self-management recommendations when required.

Web session 3 had to be delivered earlier than planned or was not delivered to some participants because of early hospital discharge. Also, components of the third in-person coaching meeting were not provided to each participant due to the time constraints associated with their hospital discharge. Hence, the timing of session delivery should be more flexible, to adjust to participant's hospital length of stay. Another option would be to deliver session 3 in-person for those who do not have internet access after hospital discharge. Moreover, patients may experience less pain to their injured extremity when no weight is put on it. Hence, booster sessions, which focus on reviewing learned self-management behaviors and establishing an individualized plan for returning to previous activities, should be scheduled after participants are allowed to fully weight bear on their injured extremity. Doing so will allow participants to re-engage in self-management behaviors required to prevent pain relapse while returning to their normal activities of daily living [62]. Likewise, considering that participants preferred to receive sessions face-to-face, the timing of session delivery should be coordinated, as much as possible, with the orthopedic surgeon appointment at the outpatient clinic.

The steps necessary to further tailor iPACT-E-Trauma could be achieved through a Sequential Multiple Assignment Randomized Trial (SMART). This type of design allows the development of adaptive interventions in which the components and the dosage of the intervention are personalized, on the basis of patient characteristics or clinical presentation. They are then repeatedly adjusted over time to individual progress [63]. Adaptive interventions include a multistage process, operationalized via a sequence of decision rules that recommend when and how the intervention should be modified, in order to maximize the effects on outcomes [63]. In a SMART, participants move through multiple stages and are randomly assigned to one of several intervention options at each stage, allowing for a comparison of their efficacy [64].

Findings related to the application of self-management behaviors also indicated that the integration of relaxation therapies to iPACT-E-Trauma must be reexamined. Relaxation therapies include a number of techniques, such as progressive muscle relaxation, guided imagery, hypnosis and deep breathing exercises [65]. In this study, only deep breathing exercises were taught. Ease of implementation in the acute care context, while also providing participants with a strategy to decrease their anxiety and its effect on pain intensity, at rest and during mobilization, made this technique relevant [66]. Nevertheless, a large proportion of participants did not practice deep breathing exercises, which could be explained by the fact that relaxation techniques require training $[46,67,68]$. Indeed, in a recent study conducted in patients with acute orthopedic trauma, with positive 
disability and pain outcomes, relaxation techniques (ie, deep breathing and progressive muscle relaxation) were taught during a 60-minute session, and patients were instructed to practice daily, guided by videos [14]. Therefore, more training time should be scheduled for participants in future applications of iPACT-E-Trauma, to optimize their use of relaxation therapies. Other techniques, such as progressive muscle relaxation, could also be offered to participants, particularly for those experiencing considerable pain inference with activities.

Another improvement to iPACT-E-Trauma relates to the feasibility of using the Web platform. Some participants needed assistance to create and enter a password at the beginning of Web sessions or did not consult actionable content (eg, Web pages on the analgesics prescribed) requiring interactions from participants with the platform to access programmed information, while most participants did not consult self-management recommendation summaries integrated in a toolbox. As many as $50 \%$ of adults have limited literacy skills [69], which may affect how they find, understand, and use information on the Web. Moreover, even users with high literacy skills may find reading and using the Web more difficult when they are sick and stressed [70]. To help developers designing digital health information tools for users with limited literacy, the Office of Disease Prevention and Health Promotion of the US Department of Health and Human Services [69] has recently developed an evidence-based guide on health literacy online. Several strategies presented in this guide could be used to overcome issues faced during Web session delivery. One of these is avoiding asking users to enter too much information. Therefore, only the participant's name could be used to access the Web sessions in iPACT-E-Trauma, since no confidential information is shared on the platform. Also, clickable elements to consult actionable content should be made more recognizable. For example, large and bright clickable buttons in a contrasting color from the surrounding text and background, and obviously clickable (eg, rectangular shape and rounded corners) could be created. Such strategies could also improve the visual appeal of the Web application, and therefore its acceptability. The summaries on self-management recommendations presented throughout Web sessions could be removed to avoid links to pages with redundant content and provided in a paper format to participants as needed.

\section{Study Strengths and Limitations}

This study is the first to assess the feasibility and acceptability of a hybrid, Web-based and in-person, intervention for the prevention of chronic pain, to be initiated in acute care settings. Nonetheless, there are some limitations that must be addressed. First, the implementation of self-management behaviors was self-reported by participants, which could have introduced a social desirability bias in the study. To avoid this, participants were invited to discuss how they applied self-management behaviors with the interventionist at each session, instead of using a formal questionnaire, which also provided the opportunity for feedback and to determine the content that needed to be reviewed. Second, it is not possible with this study to draw any conclusions on the effect of iPACT-E-Trauma. Findings from both this study and a pilot RCT [31] in which the feasibility of the research methods will also be assessed will serve for the development of a full-scale RCT. This type of study will make it possible to determine if iPACT-E-Trauma can prevent chronic pain after a major lower ET.

\section{Conclusions}

This study showed that iPACT-E-Trauma is feasible and perceived as highly acceptable by patients. Further tailoring the intervention, better support when learning deep breathing relaxation exercises, and modifying the Web platform to increase its convenience could improve both the delivery of iPACT-E-Trauma and patient satisfaction. Several studies have focused on the evaluation of self-management interventions when the pain has already become chronic. However, there is a pressing need for an intervention that can prevent disabling and costly chronic pain problems that often ensue after a major injury. The development of iPACT-E-Trauma is a milestone in the research efforts aimed at developing a relevant chronic pain preventive intervention that could be easily applied in the acute and rehabilitation continuums of care.

\section{Acknowledgments}

The first author (MB) has received fellowships from the Canadian Institutes of Health Research (MFE-140934), Fonds de recherche du Québec-Santé (FRQ-S; 30244) and Réseau de recherche en sciences infirmières du Québec (no reference number was provided) to conduct this doctoral research project. The authors received a grant from the Quebec Pain Research Network of FRQ-S (no reference number was provided) for the development of Soulage TAVIE Post-Trauma and preliminary testing in Web sessions.

We thank Laurence Lemay Belisle, Annick Gagné and Karine Tardif (Research assistants) for their support in data collection and compilation.

\section{Authors' Contributions}

MB conducted data collection and analysis in the context of her doctoral studies and drafted the manuscript. CG closely supervised data analysis and was involved in manuscript drafting. NF, GM, JC, GYL, DR, and MC provided clinical advice on data analysis and critically revised the manuscript. All authors read and approved the final manuscript.

\section{Conflicts of Interest}

None declared. 


\section{Multimedia Appendix 1}

Screenshots of Soulage TAVIE Post Trauma.

[PDF File (Adobe PDF File), 3MB-Multimedia Appendix 1]

\section{Multimedia Appendix 2}

Design of the intervention material (web sessions and participant manual) according to health literacy strategies.

[DOCX File, 26KB-Multimedia Appendix 2]

\section{References}

1. Chang MC, Stewart RM, Rotondo MF, Nathens AB. American College of Surgeons-Committee on Trauma. 2016. National Trauma Data Bank 2016, Annual Report URL: https://www.facs.org/ /media/files/quality [accessed 2018-02-28] [WebCite Cache ID 6xa08jsHo]

2. Canadian Institute for Health Information. 2013. National Trauma Registry Report 2013: Hospitalization for Major Injury in Canada URL: https://secure.cihi.ca/free products/NTR Annual Report 2013 EN.xls[WebCite Cache ID 6q5WHo09D]

3. Rosenbloom BN, Khan S, McCartney C, Katz J. Systematic review of persistent pain and psychological outcomes following traumatic musculoskeletal injury. J Pain Res 2013;6:39-51 [FREE Full text] [doi: 10.2147/JPR.S38878] [Medline: 23357964]

4. Rosenbloom BN, Katz J, Chin KYW, Haslam L, Canzian S, Kreder HJ, et al. Predicting pain outcomes after traumatic musculoskeletal injury. Pain 2016 Dec;157(8):1733-1743. [doi: 10.1097/j.pain.0000000000000580] [Medline: 27058677]

5. Clay FJ, Watson WL, Newstead SV, McClure RJ. A systematic review of early prognostic factors for persisting pain following acute orthopedic trauma. Pain Res Manag 2012;17(1):35-44 [FREE Full text] [Medline: 22518366]

6. O'Donnell ML, Varker T, Holmes AC, Ellen S, Wade D, Creamer M, et al. Disability after injury: the cumulative burden of physical and mental health. J Clin Psychiatry 2013 Feb;74(2):e137-e143. [doi: 10.4088/JCP.12m08011] [Medline: 23473359]

7. Dahm J, Ponsford J. Comparison of long-term outcomes following traumatic injury: what is the unique experience for those with brain injury compared with orthopaedic injury? Injury 2015 Jan;46(1):142-149. [doi: 10.1016/j.injury.2014.07.012] [Medline: 25123975]

8. Ponsford J, Hill B, Karamitsios M, Bahar-Fuchs A. Factors influencing outcome after orthopedic trauma. J Trauma 2008 Apr;64(4):1001-1009. [doi: 10.1097/TA.0b013e31809fec16] [Medline: 18404068]

9. Ebel BE, Mack C, Diehr P, Rivara FP. Lost working days, productivity, and restraint use among occupants of motor vehicles that crashed in the United States. Inj Prev 2004 Oct;10(5):314-319 [FREE Full text] [doi: 10.1136/ip.2004.005850] [Medline: 15470014]

10. Clay FJ, Newstead SV, Watson WL, McClure RJ. Determinants of return to work following non life threatening acute orthopaedic trauma: a prospective cohort study. J Rehabil Med 2010 Feb;42(2):162-169 [FREE Full text] [doi: 10.2340/16501977-0495] [Medline: 20140413]

11. MacKenzie EJ, Bosse MJ, Kellam JF, Pollak AN, Webb LX, Swiontkowski MF, et al. Early predictors of long-term work disability after major limb trauma. J Trauma 2006 Sep;61(3):688-694. [doi: 10.1097/01.ta.0000195985.56153.68] [Medline: $\underline{16967009]}$

12. Kendrick D, Vinogradova Y, Coupland C, Christie N, Lyons RA, Towner EL, UK Burden of Injuries Study Group. Getting back to work after injury: the UK Burden of Injury multicentre longitudinal study. BMC Public Health 2012 Aug 01;12:584 [FREE Full text] [doi: 10.1186/1471-2458-12-584] [Medline: 22853715]

13. Kendrick D, Vinogradova Y, Coupland C, Christie N, Lyons RA, Towner E, UK Burden of Injuries Study Group. Making a successful return to work: the UK burden of injury multicentre longitudinal study. Br J Gen Pract 2012 Feb;62(595):e82-e90 [FREE Full text] [doi: 10.3399/bjgp12X625139] [Medline: 22520774]

14. Vranceanu A, Hageman M, Strooker J, ter MD, Vrahas M, Ring D. A preliminary RCT of a mind body skills based intervention addressing mood and coping strategies in patients with acute orthopaedic trauma. Injury 2015 Apr;46(4):552-557. [doi: 10.1016/j.injury.2014.11.001] [Medline: 25435134]

15. Shearer HM, Carroll LJ, Wong JJ, Côté P, Varatharajan S, Southerst D, et al. Are psychological interventions effective for the management of neck pain and whiplash-associated disorders? A systematic review by the Ontario Protocol for Traffic Injury Management (OPTIMa) Collaboration. Spine J 2016 Dec;16(12):1566-1581. [doi: 10.1016/j.spinee.2015.08.011] [Medline: 26279388]

16. Linton SJ, Nordin E. A 5-year follow-up evaluation of the health and economic consequences of an early cognitive behavioral intervention for back pain: a randomized, controlled trial. Spine (Phila Pa 1976) 2006 Apr 15;31(8):853-858. [doi: 10.1097/01.brs.0000209258.42037.02] [Medline: 16622371]

17. Slater MA, Weickgenant AL, Greenberg MA, Wahlgren DR, Williams RA, Carter C, et al. Preventing progression to chronicity in first onset, subacute low back pain: an exploratory study. Arch Phys Med Rehabil 2009 Apr;90(4):545-552. [doi: 10.1016/j.apmr.2008.10.032] [Medline: 19345767] 
18. Hasenbring M, Ulrich HW, Hartmann M, Soyka D. The efficacy of a risk factor-based cognitive behavioral intervention and electromyographic biofeedback in patients with acute sciatic pain. An attempt to prevent chronicity. Spine (Phila Pa 1976) 1999 Dec 01;24(23):2525-2535. [Medline: 10626316]

19. Linton SJ, Andersson T. Can chronic disability be prevented? A randomized trial of a cognitive-behavior intervention and two forms of information for patients with spinal pain. Spine (Phila Pa 1976) 2000 Nov 01;25(21):2825-31; discussion 2824. [Medline: 11064530]

20. Linton SJ, Boersma K, Jansson M, Svärd L, Botvalde M. The effects of cognitive-behavioral and physical therapy preventive interventions on pain-related sick leave: a randomized controlled trial. Clin J Pain 2005;21(2):109-119. [Medline: 15722803]

21. Linton SJ, Ryberg M. A cognitive-behavioral group intervention as prevention for persistent neck and back pain in a non-patient population: a randomized controlled trial. Pain 2001 Feb 01;90(1-2):83-90. [Medline: 11166973]

22. Von KM, Moore JE, Lorig K, Cherkin DC, Saunders K, González VM, et al. A randomized trial of a lay person-led self-management group intervention for back pain patients in primary care. Spine (Phila Pa 1976) 1998 Dec 01;23(23):2608-2615. [Medline: 9854760 ]

23. Hay EM, Mullis R, Lewis M, Vohora K, Main CJ, Watson P, et al. Comparison of physical treatments versus a brief pain-management programme for back pain in primary care: a randomised clinical trial in physiotherapy practice. Lancet 2005;365(9476):2024-2030. [doi: 10.1016/S0140-6736(05)66696-2] [Medline: 15950716]

24. Moore JE, Von KM, Cherkin D, Saunders K, Lorig K. A randomized trial of a cognitive-behavioral program for enhancing back pain self care in a primary care setting. Pain 2000 Nov;88(2):145-153. [Medline: 11050369]

25. Lamb SE, Lall R, Hansen Z, Castelnuovo E, Withers EJ, Nichols V, BeST trial group. A multicentred randomised controlled trial of a primary care-based cognitive behavioural programme for low back pain. The Back Skills Training (BeST) trial. Health Technol Assess 2010 Aug;14(41):1-253, iii [FREE Full text] [doi: 10.3310/hta14410] [Medline: 20807469]

26. Lamb SE, Mistry D, Lall R, Hansen Z, Evans D, Withers EJ, Back Skills Training Trial Group. Group cognitive behavioural interventions for low back pain in primary care: extended follow-up of the Back Skills Training Trial (ISRCTN54717854). Pain 2012 Feb;153(2):494-501. [doi: 10.1016/j.pain.2011.11.016] [Medline: 22226729]

27. Lindell O, Johansson S, Strender L. Subacute and chronic, non-specific back and neck pain: cognitive-behavioural rehabilitation versus primary care. A randomized controlled trial. BMC Musculoskelet Disord 2008 Dec 30;9:172 [FREE Full text] [doi: 10.1186/1471-2474-9-172] [Medline: 19116007]

28. Abid Azam M, Weinrib AZ, Montbriand J, Burns LC, McMillan K, Clarke H, et al. Acceptance and Commitment Therapy to manage pain and opioid use after major surgery: Preliminary outcomes from the Toronto General Hospital Transitional Pain Service. Canadian Journal of Pain 2017 Jun 28;1(1):37-49. [doi: 10.1080/24740527.2017.1325317]

29. Flor H, Turk D. Chronic pain integrated biobehavioral perspective. Seattle: IASP Press; 2011.

30. Turk D, Flor H. The cognitive-behavioral approach to pain management. In: McMahon SB KM, editor. In Wall and Melzack's textbook of pain (5th ed). London: Elsevier Churchill Livingstone; 2006:339-348.

31. Bérubé M, Gélinas C, Martorella G, Côté J, Feeley N, Laflamme GY, et al. A Hybrid Web-Based and In-Person Self-Management Intervention to Prevent Acute to Chronic Pain Transition After Major Lower Extremity Trauma (iPACT-E-Trauma): Protocol for a Pilot Single-Blind Randomized Controlled Trial. JMIR Res Protoc 2017 Jun 26;6(6):e125 [FREE Full text] [doi: 10.2196/resprot.7949] [Medline: 28652226]

32. Bérubé M, Gélinas C, Martorella G, Feeley N, Côté J, Laflamme GY, et al. Development and acceptability assessment of a self-management intervention to prevent acute to chronic pain transition after major lower extremity trauma. Pain Man Nurse 2018 (forthcoming).

33. Gatchel RJ. Comorbidity of chronic pain and mental health disorders: the biopsychosocial perspective. Am Psychol 2004 Nov;59(8):795-805. [doi: 10.1037/0003-066X.59.8.795] [Medline: 15554853]

34. Hoffmann TC, Glasziou PP, Boutron I, Milne R, Perera R, Moher D, et al. Better reporting of interventions: template for intervention description and replication (TIDieR) checklist and guide. BMJ 2014;348:g1687 [FREE Full text] [Medline: 24609605]

35. Sidani S, Braden C. Design, Evaluation, and Translation of Nursing Interventions. Ames: John Wiley \& Sons, Inc; 2011.

36. Gewandter JS, Dworkin RH, Turk DC, Farrar JT, Fillingim RB, Gilron I, et al. Research design considerations for chronic pain prevention clinical trials: IMMPACT recommendations. Pain 2015 Jul;156(7):1184-1197. [doi: 10.1097/j.pain.0000000000000191] [Medline: 25887465]

37. Gerbershagen HJ, Aduckathil S, van WAJM, Peelen LM, Kalkman CJ, Meissner W. Pain intensity on the first day after surgery: a prospective cohort study comparing 179 surgical procedures. Anesthesiology 2013 Apr;118(4):934-944. [doi: 10.1097/ALN.0b013e31828866b3] [Medline: 23392233]

38. Unsworth A, Curtis K, Asha SE. Treatments for blunt chest trauma and their impact on patient outcomes and health service delivery. Scand J Trauma Resusc Emerg Med 2015 Feb 08;23:17 [FREE Full text] [doi: 10.1186/s13049-015-0091-5] [Medline: 25887859]

39. Teasdale G, Jennett B. Assessment of coma and impaired consciousness. A practical scale. Lancet 1974 Jul 13;2(7872):81-84. [Medline: 4136544]

40. American COSCOT. Alcohol and Injury. 2017 URL: http://wwww.wbcitation.org/6xa1TsXdE [accessed 2017-09-10] [WebCite Cache ID 6xa1TsXdE] 
41. Parry-Jones BL, Vaughan FL, Miles Cox W. Traumatic brain injury and substance misuse: A systematic review of prevalence and outcomes research (1994-2004). Neuropsychological Rehabilitation 2011 Feb 16;16(5):537-560. [doi: $10.1080 / 09602010500231875]$

42. Taylor LA, Kreutzer JS, Demm SR, Meade MA. Traumatic brain injury and substance abuse: A review and analysis of the literature. Neuropsychol Rehabil 2003 Jan;13(1-2):165-188. [doi: 10.1080/09602010244000336]

43. US Department of Transportation - National Highway Traffic Safety Administration. 2010. Drug Involvement of Fatally Injured Drivers URL: https://crashstats.nhtsa.dot.gov/Api/Public/ViewPublication/811415 [accessed 2017-09-10] [WebCite Cache ID 6xa1apZ3F]

44. Jensen MP, Turk DC. Contributions of psychology to the understanding and treatment of people with chronic pain: why it matters to ALL psychologists. Am Psychol 2014;69(2):105-118. [doi: 10.1037/a0035641] [Medline: 24547797]

45. Côté J, Ramirez-Garcia P, Rouleau G, Saulnier D, Guéhéneuc Y, Hernandez A, et al. A nursing virtual intervention: real-time support for managing antiretroviral therapy. Comput Inform Nurs 2011;29(1):43-51. [doi: 10.1097/NCN.0b013e3181f9dc02] [Medline: 21099544]

46. Martorella G, Côté J, Choinière M. SOULAGE-TAVIE: development and validation of a virtual nursing intervention to promote self-management of postoperative pain after cardiac surgery. Comput Inform Nurs 2013 Apr;31(4):189-197. [doi: 10.1097/NXN.0b013e3182812d69] [Medline: 23438864]

47. U.S. Department of Health and Human Services - Center for Disease Control and Prevention. Simply Put. Atlanta: Strategic and Proactive Communication Branch - Division of Communication Services; 2009. URL: https://www.cdc.gov/healthliteracy/ pdf/Simply_Put.pdf [accessed 2017-09-15] [WebCite Cache ID 6yQzZjcpH]

48. U.S. Department of Health and Human Services. Health literacy online: A guide to writing and designing easy-to-use health Web sites. Washington: Office of Disease Prevention and Health Promotion URL: https://health.gov/healthliteracyonline/ 2010/Web_Guide_Health_Lit_Online.pdf [accessed 2018-04-04] [WebCite Cache ID 6yQzomCi0]

49. Perepletchikova F, Kazdin A. Treatment integrity and therapeutic change: Issues and research recommendations. Clin Psychol Sci Pract 2005;12(4):365-383. [doi: 10.1093/clipsy.bpi045]

50. Côté J, Rouleau G, Godin G, Ramirez-Garcìa P, Guéhéneuc Y, Nahas G, et al. Acceptability and feasibility of a virtual intervention to help people living with HIV manage their daily therapies. J Telemed Telecare 2012 Oct;18(7):409-412. [doi: 10.1258/jtt.2012.120218] [Medline: 23034932]

51. Sidani S, Epstein DR, Bootzin RR, Moritz P, Miranda J. Assessment of preferences for treatment: validation of a measure. Res Nurs Health 2009 Aug;32(4):419-431 [FREE Full text] [doi: 10.1002/nur.20329] [Medline: 19434647]

52. Palmer C. Major trauma and the injury severity score-where should we set the bar? Annu Proc Assoc Adv Automot Med 2007;51:13-29 [FREE Full text] [Medline: 18184482]

53. Hawkins RP, Kreuter M, Resnicow K, Fishbein M, Dijkstra A. Understanding tailoring in communicating about health. Health Educ Res 2008 Jun;23(3):454-466 [FREE Full text] [doi: 10.1093/her/cyn004] [Medline: 18349033]

54. Kreuter M, Farrell D, Olevitch L, Brennan L. Tailoring Health Messages: Customizing Communication with Computer Technology. New York: Routledge - Taylor \& Francis Group; 2012.

55. Plow M, Mangal S, Geither K, Golding M. A Scoping Review of Tailored Self-management Interventions among Adults with Mobility Impairing Neurological and Musculoskeletal Conditions. Front Public Health 2016;4:165 [FREE Full text] [doi: 10.3389/fpubh.2016.00165] [Medline: 27672633]

56. Lustria MLA, Noar SM, Cortese J, Van SSK, Glueckauf RL, Lee J. A meta-analysis of web-delivered tailored health behavior change interventions. J Health Commun 2013;18(9):1039-1069. [doi: 10.1080/10810730.2013.768727] [Medline: 23750972]

57. Noar SM, Benac CN, Harris MS. Does tailoring matter? Meta-analytic review of tailored print health behavior change interventions. Psychol Bull 2007 Jul;133(4):673-693. [doi: 10.1037/0033-2909.133.4.673] [Medline: 17592961]

58. Krebs P, Prochaska JO, Rossi JS. A meta-analysis of computer-tailored interventions for health behavior change. Prev Med 2010;51(3-4):214-221 [FREE Full text] [doi: 10.1016/j.ypmed.2010.06.004] [Medline: 20558196]

59. Martorella G, Boitor M, Bérubé M, Fredericks S, Lemay S, Gélinas C. Tailored Web-Based Interventions for Pain: Systematic Review and Meta-Analysis. J Med Internet Res 2017 Nov 10;19(11):e385 [FREE Full text] [doi: 10.2196/jmir.8826] [Medline: 29127076]

60. Kelders SM, Kok RN, Ossebaard HC, Van Gemert-Pijnen JEWC. Persuasive system design does matter: a systematic review of adherence to web-based interventions. J Med Internet Res 2012;14(6):e152 [FREE Full text] [doi: 10.2196/jmir.2104] [Medline: 23151820]

61. Baumeister H, Reichler L, Munzinger M, Lin J. The impact of guidance on Internet-based mental health interventions A systematic review. Internet Interventions 2014 Oct;1(4):205-215. [doi: 10.1016/j.invent.2014.08.003]

62. Yardley L, Spring BJ, Riper H, Morrison LG, Crane DH, Curtis K, et al. Understanding and Promoting Effective Engagement With Digital Behavior Change Interventions. Am J Prev Med 2016 Nov;51(5):833-842. [doi: 10.1016/j.amepre.2016.06.015] [Medline: 27745683]

63. Lei H, Nahum-Shani I, Lynch K, Oslin D, Murphy SA. A SMART design for building individualized treatment sequences. Annu Rev Clin Psychol 2012;8:21-48 [FREE Full text] [doi: 10.1146/annurev-clinpsy-032511-143152] [Medline: 22224838] 
64. Murphy SA. An experimental design for the development of adaptive treatment strategies. Stat Med 2005 May 30;24(10):1455-1481. [doi: 10.1002/sim.2022] [Medline: 15586395]

65. National Institutes of Health - National Center for Complementary and Integrative Health. 2016. Relaxation Techniques for Health URL: https://nccih.nih.gov/health/stress/relaxation.htm [accessed 2017-10-10] [WebCite Cache ID 6xa0yBGku]

66. Wong EM, Chan SW, Chair S. Effectiveness of an educational intervention on levels of pain, anxiety and self-efficacy for patients with musculoskeletal trauma. J Adv Nurs 2010 May;66(5):1120-1131. [doi: 10.1111/j.1365-2648.2010.05273.x] [Medline: 20337801]

67. Ehde DM, Dillworth TM, Turner JA. Cognitive-behavioral therapy for individuals with chronic pain: efficacy, innovations, and directions for research. Am Psychol 2014;69(2):153-166. [doi: 10.1037/a0035747] [Medline: 24547801]

68. Vickers A, Zollman C, Payne DK. Hypnosis and relaxation therapies. West J Med 2001 Oct;175(4):269-272 [FREE Full text] [Medline: 11577062]

69. U.S. Department of Health and Human Services - Office of Disease Prevention and Health Promotion. 2016. Health Literacy Online URL: https://health.gov/healthliteracyonline/ [accessed 2018-02-28] [WebCite Cache ID 6xa15VBtT]

70. Jarrett C, Gaffney G. Forms that work: Designing Web forms for usability. San Francisco: Morgan Kaufmann/Elsevier; 2009.

\author{
Abbreviations \\ AIS: Abbreviated Injury Scale \\ iPACT-E-Trauma: Intervention to prevent acute to chronic pain after major lower extremity trauma \\ ET: extremity trauma \\ ISS: Injury Severity Score \\ TAP: Treatment and acceptability preference \\ TAVIE: Traitement et Assistance Virtuelle Infirmière et Enseignement
}

Edited by G Eysenbach; submitted 06.03.18; peer-reviewed by J Katz, R Lee; comments to author 28.03.18; revised version received
11.04.18; accepted 14.04.18; published 30.04.18
Please cite as:
Bérubé M, Gélinas C, Feeley N, Martorella G, Côté J, Laflamme GY, Rouleau DM, Choinière M
A Hybrid Web-Based and In-Person Self-Management Intervention Aimed at Preventing Acute to Chronic Pain Transition After Major
Lower Extremity Trauma: Feasibility and Acceptability of iPACT-E-Trauma
JMIR Formativ Res 2018;2(1):e10323
URL: $\underline{\text { http:/lformative.jmir.org/2018/1/e10323/ }}$
doi: $\underline{10.2196 / 10323}$
PMID: $\underline{30684418}$

CMélanie Bérubé, Céline Gélinas, Nancy Feeley, Géraldine Martorella, José Côté, G Yves Laflamme, Dominique M Rouleau, Manon Choinière. Originally published in JMIR Formative Research (http://formative.jmir.org), 30.04.2018. This is an open-access article distributed under the terms of the Creative Commons Attribution License (https://creativecommons.org/licenses/by/4.0/), which permits unrestricted use, distribution, and reproduction in any medium, provided the original work, first published in JMIR Formative Research, is properly cited. The complete bibliographic information, a link to the original publication on http://formative.jmir.org, as well as this copyright and license information must be included. 